\title{
Editorial: Why do We Choose to Address Health 2020?
}

\author{
Antoine Flahault, $\mathrm{MD}, \mathrm{PhD}, 1,2$ \\ José M. Martin-Moreno, MD, PhD, DrPH ${ }^{3,4}$
}

Recommended Citation: Flahault A, Martin-Moreno JM. Why do we choose to address health 2020? Public Health Reviews. 2013;35: epub ahead of print.

What can we predict for 2020? Solar and lunar eclipses? Without a doubt. Climate change? Most likely. Rising sea levels? Signs point to yes. Beyond that, however, in the world of human events, it is best to be cautious. In the field of health and medicine (or anywhere else, for that matter), no one predicted the most important discoveries of the twentieth century. Economists were no more successful in foreseeing financial or economic crises. The pundits did not forecast any of the recent wars, disruptions or even the recent Arab Spring movements-indeed, political experts turned out to be only slightly more accurate than dart-throwing chimpanzees in divining what was in store for the future. ${ }^{1}$ As the World Health Organization (WHO) and the wider scientific community looked to East Asia in anticipation of the next outbreak of H5N1, the influenza H1N1 pandemic took hold in Mexico. Tsunamis, volcanic eruptions, earthquakes, drug scandals, outbreaks of emerging diseases and political disruptions are notoriously unpredictable, as Nassim Nicholas Taleb brilliantly highlighted in his book The Black Swan. ${ }^{2}$

Under these circumstances, where change is the only constant, Peter Drucker used to say that we have to prepare for "the future that has already happened", ${ }^{3}$ that is, we must examine our present to glean clues about our future. When Charles Townes's research on light diffraction led to the invention of the laser, he could not foresee the thousands of applications it would have in the field of home video and music, nor the major impact in eye surgery and medicine. But innovative scientists and engineers transformed it into a tremendously beneficial tool for humankind by envisaging the potential fruit of a tree whose seed had only just been planted.

\footnotetext{
${ }^{1}$ L'Université Paris Descartes, Sorbonne Paris Cité, Paris, France.

${ }^{2}$ Editor in Chief, Public Health Reviews, Paris and Rennes, France.

${ }^{3}$ Faculty of Medicine and Dentistry, Universidad de Valencia, Valencia Spain.

${ }^{4}$ Head of Central Quality Unity, Hospital Clínico Universitario de Valencia, Valencia, Spain.
} 
Policymakers and public health professionals are thusly charged with preparing health systems and populations for future challenges as best as possible, relying upon the knowledge available to us now. There are some weighty trends whose mechanisms have already been set into motion; these will to a great extent shape our future. Demographic trends within populations and workforces, current prevalence of important disease determinants (obesity, smoking)... these are fundamentally reliable indicators that we can use to plan for appropriate health system responses. While we cannot shut the door on the surprises that the future holds, it is highly probable that up to 2030, cancers, coronary heart diseases and stroke will remain, the three primary causes of mortality in developed countries. ${ }^{4}$ It is also foreseeable that unipolar depression, diabetes and dementias will become the foremost causes of burden of diseases in these settings. ${ }^{4}$

Beyond those trends, it is difficult to predict the breakthroughs that will change people's lives and revolutionize how we deal with disease. A few months ago, we might have imagined that stenting would dramatically change the prognosis of stroke in intracranial stenosis. Yet, a 450-patient randomized trial was stopped early due to increased mortality one year after treatment in the intervention arm. ${ }^{5}$ It is hard to anticipate if mammography will remain the gold standard for early detection of breast cancer due to emerging doubts and controversy raised about its true efficacy. ${ }^{6}$ By contrast, early detection of lung cancer with spiral low dose tomodensitometry may be recommended in the near future, after the publication of a large NIH-funded clinical trial involving more than 50,000 heavy smokers or former heavy smokers aged 55 to 74.7 This trial was also terminated early, but in this case it was due to a significant decrease in all causes mortality, as well as in lung cancer specific mortality. Promising breakthroughs against two of the scourges of the developing world, malaria ${ }^{8}$ and HIV/AIDS, ${ }^{9}$ could also dramatically change the global disease burden.

Other new developments will increase the demand for new skills and competencies in public health agencies. In drug safety, for example, computer assisted data mining may progressively replace old clinical or pharmaceutical assessment of side effects. A team from Harvard recently developed a tool using big data approaches, which combined data mining with mathematical and statistical modeling to explore the potential for forecasting adverse effects. ${ }^{10}$ A validation sample showed that their models would have been powerful in making such predictions, which could help pharmaceutical industries and health authorities to prevent disasters in drug safety.

We can only speculate on which country will rank first in tobacco control. Sweden, whose tough anti-tobacco policies include smoking bans in public settings, increases in cigarette tax, and warnings on package 
labeling, paradoxically has one of the highest levels of oral tobacco use in OECD countries. This use of smokeless tobacco, although not well assessed, probably has a much lower impact on health than smoking tobacco, with possibly no propensity to lead to cancer or cardiovascular disease. This form of consumption, as well as others such as electronic cigarettes, will likely result in changes to the smoking-related disease pattern in the future; however, what those changes will be is a question still open to debate.

In 2020, genomics and genetics will probably have led to further progress. To what extent they will impact public health remains to be seen, but a new discipline known as "public health genomics" is emerging to explore the potential. Today, online services are offering tests to detect rare genetic diseases (e.g., more than 150 tests on a chip), which are already being reimbursed by health plans in the United States. It is still premature to speculate that this type of testing will become routine in the future, but it is undoubtedly a topical public health issue, with possibly serious ethical and legal implications.

In the same line of reasoning, nanotechnologies are also growing quickly in the field of health and medicine, with tremendous promise for human health. Today, pancreatic cancer is among the tumors whose prognosis is the most grim, but tomorrow, the novel, low-cost application of carbon nanotubes to detect mesothelin biomarkers developed by 15 yearold Jack Andraka could conceivably bring survival rates in line with those seen in breast cancers. ${ }^{11}$ Patients with chronic disease, such as type II diabetes, may also stand to benefit, and public health surveillance and monitoring could be substantially improved.

Just as important to consider as what the benefits of all these new technologies will be, is how to guarantee their universal access when proven effective. Patient empowerment, globalization, the spread of democracy, mobile technology and the internet are all factors that contribute to the breakdown of the status quo, and it is no longer tolerable to imagine that only a privileged few will be able to screen against disease, benefit from the best surveillance, or have access to high tech devices for their health. Citizens increasingly occupy - rightfully so-centre stage in the health system, and they will be crucial to guaranteeing the quality and legitimacy of any public health plan. In the United States, the Patient Protection and Affordable Care Act has led to the creation of the Patient-Centered Outcome Research Institute (PCORI), funded by US $\$ 1$ billion from the federal budget; the organization is charged with performing comparative clinical effectiveness research in close association with patients' associations. Elsewhere, the influence of social networks and NGOs is also growing, entailing a tremendous impact on political decisions, transparency and 
accountability issues, and participation in formulating innovative measures to collectively improve health through longer and better-quality lives.

All of the above considerations pose considerable challenges to the question of how we can best equip our health systems to respond to the known and unknown threats to future health. Money is certainly an issue, but, as Avedis Donabedian wrote, there is a "point of optimality", ${ }^{12}$ after which investment of resources may not be associated with an increase in population net benefit, due to continuous and linear increase in population harm. The exact coordinates of this point of optimality is far from clear in most instances, but we can surmise that health system performance is just as important as the financing that enables it to function.

Despite all the enigmas shrouding the future, health systems do not have the luxury of improvisation: It takes years, if not decades, to roll out programs that are sufficiently funded, staffed and equipped, requiring health systems to be proactive in their preparations. Planners must consider the current and future disease burden (almost certain to be dominated by chronic illness), potential but unpredictable threats such as infectious disease outbreaks, and emerging tools that can aid public health practitioners. Plans must also contextualize the health system within other social and economic trends: the (ongoing) financial crisis, the communication revolution, technological innovation, and the horizontalization of government policy. In fact, conventional wisdom has come to accept the fact that health outcomes greatly depend on disease determinants that originate in multiple sectors of society, not just in the health system. Effective health promotion and protection will only be possible through intersectoral action, leading to a paradigm shift in which governance for health (rather than health governance) emerges as the most comprehensive and effective way to realize a true whole-of-government/ whole-of society approach. Only with these complex considerations in mind can countries begin to develop strategies for the future, and these must then be capable of adapting quickly to unfolding events.

This thematic issue will examine several countries that have developed plans for 2020, including the American Healthy People 2020 and Healthy Israel 2020. These two countries illustrate the differences-but also the similarities - between diverse health systems and the approaches they take towards preparing for the future. The goals are obviously the same: anticipating future trends and needs as well as proposing targets to reach. But their methods are notably different.

The United States is more familiar with this exercise, since as early as 1979 , there have been national goals in public health, with successive tenyear plans at a federal level since 1990. Success of past policy has been mixed. In 2010, for example, the objective related to prevalence of type II 
diabetes (below 3.8 cases per 1,000 adults) was not reached, remaining above 8.0, while the target for mortality due to coronary heart disease was attained by 2004, and the trend was still favorable and better than anticipated six years later. In the ongoing plan covering the decade 2011-2020, there are 12 priorities, with 26 indicators drawn from a catalogue of 600 objectives according to 42 domains and including more than 1,200 intervention measures. This new plan represents a real attempt to prioritize public health intervention at a federal level, including a wide range of topics such as environmental health, mental health, oral health, and social determinants of health. Targets are clearly defined and measurable.

On the other side of the world, Israel has proposed a truly innovative approach with Healthy Israel 2020. The plan's 30 actions include promoting physical activity, preventing alcohol-related diseases and promoting mental health. Like plans from other countries, it also includes a number of targets; however, unlike its counterparts, a method for how to reach them is also delineated. Integrated approaches for the proposed strategies and interventions have been formulated and adopted, involving local authorities, communities, employers, educators, media and social marketing activists, healthcare professionals and legislators, as well as supportive measures to monitor and evaluate progress. All proposals were carefully and extensively documented against available international evidence in order to elaborate something truly elusive and far too singular: real evidence-based policy.

Public Health Reviews is proud to dedicate this thematic issue to the future of public health in the United States, Europe, and the world, shedding light on the complex factors that will feed into heath system responses and highlighting a number of splendid initiatives underway across the globe. We hope that the critical assessments (and the occasional disagreements) from experts and researchers who rank among the best in these fields will aid in our collective understanding of how to best achieve agile, resourceful health systems capable of protecting and improving health for all populations.

\section{REFERENCES:}

1. Tetlock PE. Expert Political Judgment: How Good Is It? How Can We Know? Princeton, NJ: Princeton University Press; 2005.

2. Taleb NN. The Black Swan: The Impact of the Highly Improbable. New York, NY: Random House; 2nd edition, 2010.

3. Drucker P. On the Profession of Management. Boston, MA: Harvard Business School Press; 2003.

4. Mathers CD, Loncar D. Projections of global mortality and burden of disease from 2002 to 2030. PLoS Med 2006;3:e442. 
5. Chimowitz MI, Lynn MJ, Derdeyn CP, Turan TN, Fiorella D, et al. Stenting versus aggressive medical thearapy for intracranial arterial stenosis. N Engl J Med. 2011;365:993-1003.

6. Bleyer A, Welch HG. Effect of three decades of screening mammography on breast-cancer incidence. N Engl J Med. 2012;367:1998-2005.

7. The National Lung Screening Trial Research Team. Reduced lung-cancer mortality with low-dose computed tomographic screening. N Engl J Med. 2011;365:395-409.

8. Nilsen A, LaCrue AN, White KL, Forquer IP, Cross RM, et al. Quinolone-3diarylethers: a new class of antimalarial drug. Sci Trans Med. 2013;5:177ra37.

9. Sáez-Cirión A, Bacchus C, Hocqueloux L, Avettand-Fenoel V, Girault I, et al. Post-treatment HIV-1 controllers with a long-term virological remission after the interruption of early initiated antiretroviral therapy ANRS VISCONTI Study. PLoS Pathog. 2013;9:e1003211.

10. Cami A, Arnold A, Manzi S, Reis B. Predicting adverse drug events using pharmacological network models. Sci Transl Med. 2011;3:114ra127.

11. Tucker A. Jack Andraka, the teen prodigy of pancratic cancer. Smithsonian. December 2012. Available from URL : http://www.smithsonianmag.com/ science-nature/Jack-Andraka-the-Teen-Prodigy-of-Pancreatic-

Cancer-179996151.html (Accessed 25 July 2013).

12. Donabedian A. An Introduction to Quality Assurance in Health Care. New York, NY; Oxford University Press: 2002. 